\title{
Effects of passive smoking on the pulmonary function of adults
}

\author{
Mohammad-Reza Masjedi, Homayoun Kazemi, Douglas C Johnson
}

\begin{abstract}
The effects of exposure to environmental tobacco smoke (passive smoking) on pulmonary function of non-smoking, healthy Iranian men $(n=167)$ and women $(n=108)$ were investigated. There were significant reductions in $\%$ predicted FEV $_{1}(5 \cdot 7 \%$ ), forced vital capacity (FVC, $4.6 \%$ ) and forced expiratory flow $25-75 \%$ FEF $_{25-75}, 9.9 \%$ ) among men exposed to cigarette smoke $(n=78)$. The adverse effect of passive smoking was greatest among men exposed at the workplace (reduction in \% predicted FEV $19.4 \%$, FVC $7 \cdot 6 \%$, and FEF $_{25-75} 15 \cdot 3 \%$ ). No significant difference in pulmonary function was found among the 54 women exposed to passive smoke, but only eight women had smoke exposure at work. It is concluded that exposure to environmental tobacco smoke, particularly at the workplace, adversely affects the pulmonary function of adults.
\end{abstract}

Cigarette smoking is the major cause of preventable diseases, including cardiovascular disease, lung cancer, and chronic obstructive pulmonary disease. Involuntary exposure to environmental tobacco smoke also carries many hazards. ${ }^{12}$ Exposure to cigarette smoke or passive smoking has been associated with a higher risk of lung cancer in adults, and with increased frequency of respiratory infections and symptoms in children. ${ }^{1-5}$ Parental smoking is associated with reduced pulmonary function in children. ${ }^{6-11}$

Relatively few studies have evaluated the effects of environmental tobacco smoke on pulmonary function in adults. ${ }^{912-16}$ The current study compares the pulmonary function of healthy, non-smoking Iranian adults who were and were not exposed to environmental tobacco

\section{Department of}

Medicine, Pulmonary

and Critical Care

Unit, Massachusetts

General Hospital, and

Harvard Medical

School, Boston,

Massachusetts, USA

M-R Masjedi

H Kazemi

D C Johnson

Address for reprint requests: Dr Douglas C Johnson Pulmonary and Critical Care Unit, Massachusetts General Hospital, Boston,

Massachusetts 02114, USA.

Accepted 3 October 1989

We tested 288 male and female non-smokers aged 18-65 years living in Tehran. They consisted of volunteers attending a medical conference, hospital workers, or visitors to the hospital. A questionnaire was used to collect the following information from each subject: personal data, age, sex, date of birth, place of growing up, and occupation. Subjects were excluded from the study if there was any history of wheezing, current cough, dyspnoea, sputum production, asthma, allergic rhinitis, hay fever, urticaria, other allergic conditions, smoke.

cardiac disease, chest deformity, or occupational exposure to hazardous substances. None of the subjects had ever smoked. For those subjects who reported exposure to cigarette smoke, information was obtained about the place of exposure (home, workplace, or both) and who the smoker was at home (father, mother, brother, sister, spouse, or other). We also requested information on the period of passive exposure to cigarette smoke, and the number of cigarettes consumed daily by the smoker, and on prenatal exposure to cigarette smoke, but there were insufficient responses to these questions to allow further analysis.

The investigation was carried out in Tehran. Height and weight were measured without shoes and with light clothing. Oral temperature was measured. Ambient atmospheric pressure, humidity, and temperature were recorded daily (mean room temperature $22.9^{\circ} \mathrm{C}$, mean atmospheric pressure $666 \mathrm{~mm} \mathrm{Hg}$ ). The tests were done with the subject sitting and wearing a noseclip. Spirometry was carried out with a Vitalograph bellows spirometer that met the American Thoracic Society criteria ${ }^{17}$ for measurement of forced vital capacity (FVC), forced expiratory volume in the first second of FVC $\left(\mathrm{FEV}_{1}\right)$, and forced expiratory flow $25-75 \%\left(\mathrm{FEF}_{25-75}\right)$. The maximum volume was used for FVC. The time zero for $\mathrm{FEV}_{1}$ was determined by the back extrapolation method; the back extrapolation volume was always under $5 \%$ of the FVC. The $\mathrm{FEF}_{25-75}$ was determined from the volume-time curve with the largest sum of FVC and FEV . Peak expiratory flow (PEF) was measured with a Wright peak flow meter. Each subject carried out at least three spirometry manoeuvres and three PEF determinations. If there was more than a $5 \%$ difference between the two best FVC or PEF values, that value was discarded. For FVC, $\mathrm{FEV}_{1}$, and PEF the highest values were used for subsequent analysis. All volumes were recorded at room temperature and converted from ATPS to BTPS.

\section{STATISTICAL ANALYSIS}

Values are expressed as means and standard errors, except for age and height, which are given as means and standard deviations. Multivariate regression analysis was used to obtain regression formulas for BTPS values on the basis of age and height. As our hypothesis was that exposure to environmental tobacco smoke would cause decrements in pulmonary function, we used a one tailed unpaired $t$ test to compare the two groups. Analysis of variance 
Table 1 Mean (SEM) age, height, and pulmonary function values (\% predicted) in male passive smokers and in non-exposed men: comparison in all men, all those aged less than 50 , and age matched men

\begin{tabular}{|c|c|c|c|c|c|c|}
\hline & \multicolumn{2}{|l|}{ All men } & \multicolumn{2}{|l|}{ Men under 50} & \multicolumn{2}{|c|}{ Age matched men } \\
\hline & Passive & Non-exposed & Passive & Non-exposed & Passive & Non-exposed \\
\hline $\begin{array}{l}\text { Number } \\
\text { Age (y) } \\
\text { Height (cm) } \\
\text { FEV }_{1}(\%) \\
\text { FVC }(\% \%) \\
\text { FEF }_{25-75}(\%) \\
\left.\operatorname{PEF}^{2} \%\right)\end{array}$ & $\begin{array}{l}78 \\
27 \cdot 7(1 \cdot 0)^{\star \star} \\
172 \cdot 7(0 \cdot 7) \\
96 \cdot 9(1 \cdot 3)^{\star \star} \\
97 \cdot 5(1 \cdot 3)^{\star \star} \\
94 \cdot 4(2 \cdot 8)^{\star} \\
98 \cdot 8(1 \cdot 3)\end{array}$ & $\begin{array}{l}89 \\
34 \cdot 1(1 \cdot 3) \\
171 \cdot 1(0 \cdot 7) \\
102 \cdot 6(1 \cdot 4) \\
102 \cdot 1(1 \cdot 2) \\
104 \cdot 3(3 \cdot 3) \\
100 \cdot 9(1 \cdot 5)\end{array}$ & $\begin{array}{l}76 \\
27 \cdot 1(1 \cdot 0)^{\star \star} \\
172 \cdot 7(0 \cdot 7) \\
97 \cdot 0(1 \cdot 3)^{\star \star} \\
97 \cdot 8(1 \cdot 3)^{\star} \\
94 \cdot 1(2 \cdot 8)^{\star} \\
98 \cdot 4(1 \cdot 3)^{\star \star}\end{array}$ & $\begin{array}{l}77 \\
30 \cdot 5(1 \cdot 0) \\
171 \cdot 4(0 \cdot 7) \\
102 \cdot 2(1 \cdot 3) \\
102 \cdot 0(1 \cdot 3) \\
103 \cdot 8(3 \cdot 2) \\
101 \cdot 7(1 \cdot 5)\end{array}$ & $\begin{array}{l}46 \\
28 \cdot 4(1 \cdot 3) \\
172 \cdot 4(1 \cdot 0) \\
96 \cdot 2(1 \cdot 6)^{\star \star} \\
97 \cdot 9(1 \cdot 6)^{\star} \\
91 \cdot 1(3 \cdot 6)^{\star \star} \\
97 \cdot 2(1 \cdot 7)\end{array}$ & $\begin{array}{l}46 \\
28 \cdot 4(1 \cdot 3) \\
171 \cdot 0(0 \cdot 8) \\
103 \cdot 5(1 \cdot 7) \\
103 \cdot 0(1 \cdot 7) \\
106 \cdot 5(4 \cdot 1) \\
103 \cdot 6(1 \cdot 9)\end{array}$ \\
\hline
\end{tabular}

${ }^{\star} \mathrm{p}<0.01 ;{ }^{\star \star} \mathrm{p}<0.005$ in the comparison with non-exposed subjects (one tailed $t$ test).

$\mathrm{FEV}_{1}$ - forced expiratory volume in one second; FVC-forced vital capacity; $\mathrm{FEF}_{25-75}$-forced expiratory flow $25-75 \%$; PEFpeak expiratory flow.

(the Dunnett method) was used to compare several groups against one control group. Values of $\mathrm{p}$ less than 0.05 were deemed significant.

\section{Results}

Of the 288 subjects examined, 13 were excluded: two in whom a history of smoking became apparent, four with a history of allergic rhinitis, two with chest deformity, and five because of unreproducible spirometry values. Of the 275 study subjects, 167 were male and 108 were female.

The male subjects ranged in age from 17 to 65 years (mean $31 \cdot 1(11 \cdot 3)$ ). The age distribution was as follows: 23 subjects were 17-20 years, 69 21-30, 42 31-40, $1941-50,11$ 51-60, and three $61-65$. Their height ranged from 154 to $192(171.8(6.2) \mathrm{cm})$. There were 81 students, 33 white collar employees, 28 labourers, 16 medical technicians or nurses, and nine physicians.

The female subjects ranged in age from 18 to $65(31.5(11.9)$ years). Their age distribution was as follows: nine subjects were 18-20 years, $5621-30,2331-40$, seven $41-50,1151-60$, and two 61-65. Their height ranged from 144 to $172(159 \cdot 6(5.2) \mathrm{cm})$. Of the 108 subjects, there were 40 students, 39 medical technicians and nurses, 18 housewives, eight white collar employees, and three labourers.

\section{PASSIVE SMOKERS}

Male subjects Of the 167 men, $78(47 \%)$ were passive smokers. The distribution of occupations of the male passive smokers was similar to that of the non-exposed men (43 students, 16 white collar employees, nine labourers, eight medical technicians and nurses, and two physicians), except that a smaller number of labourers were passive smokers. Forty seven $(62 \%)$ of the passive smokers were exposed to smoke at home, 16 at work, and 15 at both places. For 45 of the 47 passive smokers who were exposed at home the father was the smoker. Passive smokers were younger than the non-exposed subjects $(27.7(9.0) v 34.1(12.3)$ years; $p<0.05$; table 1$)$. Height was similar in the exposed and non-exposed group. Passive smokers had lower \% predicted values for $\mathrm{FEV}_{1}, \mathrm{FVC}, \mathrm{FEF}_{25-75}$ but similar PEF values. As the age of the passive smokers and nonexposed group differed further analyses were performed. The same relations were found among subjects 50 years old or younger (76 passive smokers, and 77 non-exposed). When 92 age matched subjects were compared, passive smokers had significantly lower \% predicted values for all measurements, including PEF.

Passive smokers were divided into subgroups according to the source of exposure to investigate the effect of the type of exposure to cigarette smoke (table 2). Values for \% predicted $\mathrm{FEV}_{1}, \mathrm{FVC}$, and $\mathrm{FEF}_{25-75 \%}$ were lower $(p<0.05)$ for subjects exposed at work than for non-exposed subjects. In the subgroup exposed to smoke only at work $\% \mathrm{FEV}_{1}$ and $\%$ FVC were lower $(p<0.05)$, and for those exposed at work and home \% FEV 1 was significantly lower. No reductions were seen in those exposed only at home.

Female subjects Of the 108 female subjects, 54 $(50 \%)$ were passive smokers, including 17 students, 26 medical technicians and nurses, four housewives, four white collar employees, and three labourers. The passive smokers included more medical technicians and nurses, fewer housewives, and more labourers than the non-exposed group. Forty six passive smokers $(85 \%)$ were exposed at home, four at work, and four at both places. The father was the smoker for 27 subjects exposed at home. Age and height were similar in the passive smoking and non-exposed subjects (table 3 ). There were no significant differences between the nonexposed subjects and the passive smokers in $\%$ predicted spirometric values among the group

Table 2 Mean (SEM) pulmonary function values (\% predicted), age, and height: comparison of non-exposed men and subgroups of male passive smokers

\begin{tabular}{|c|c|c|c|c|c|c|c|}
\hline & $n$ & $F E V_{1}(\%)$ & $F V C(\%)$ & $F E F_{25-75}(\%)$ & $P E F(\%)$ & Age (y) & Height $(\mathrm{cm})$ \\
\hline $\begin{array}{l}\text { Non-exposed } \\
\mathbf{W} \\
\mathbf{W}+\mathbf{H} \\
\mathbf{W}+ \\
\mathbf{H}\end{array}$ & $\begin{array}{l}89 \\
16 \\
15 \\
31 \\
43\end{array}$ & $\begin{array}{c}102.6(1.4) \\
92 \cdot 8(2 \cdot 5) \dagger \\
93.6(2.9) \dagger \\
93.2(1.8) \dagger \\
98.4(1.7)\end{array}$ & $\begin{array}{c}102 \cdot 1(1 \cdot 2) \\
93 \cdot 6(3 \cdot 0) \dagger \\
95 \cdot 5(3 \cdot 1) \\
94 \cdot 5(2 \cdot 1) \dagger \\
99 \cdot 3(1 \cdot 7)\end{array}$ & $\begin{array}{c}104 \cdot 3(3 \cdot 3) \\
89 \cdot 7(4 \cdot 8) \\
88 \cdot 1(4 \cdot 6) \\
89 \cdot 0(3 \cdot 2) \dagger \\
93 \cdot 6(3.6)\end{array}$ & $\begin{array}{r}100.9(1.5) \\
97.6(2.3) \\
97.1(3.9) \\
97.3(2.1) \\
98.7(1.8)\end{array}$ & $\begin{array}{l}34.1(1.3) \\
33.3(1.9) \\
29.8(2.2) \\
31.6(1.9) \\
24.9(0.9) \dagger\end{array}$ & $\begin{array}{l}171.1(0.7) \\
174.3(1.4) \\
172.9(1.5) \\
173.6(1.2) \\
172.2(0.9)\end{array}$ \\
\hline
\end{tabular}

W-those exposed at work only; $\mathbb{W}+\mathrm{H}$-those exposed both at work and at home; $\mathrm{W}+$-those exposed at work with or without exposure at home; $\mathrm{H}$-those exposed at home only. $+\mathrm{p}<0.05$ in the comparision with non-exposed subjects.

Abbreviations as in table 1 . 
Table 3 Mean (SEM) age, height, and pulmonary function values (\% predicted) in female passive smokers and in non-exposed women: comparison in all women and age matched women

\begin{tabular}{|c|c|c|c|c|}
\hline & \multicolumn{2}{|l|}{ All women } & \multicolumn{2}{|c|}{ Age matched women } \\
\hline & Passive & Non-exposed & Passive & Non-exposed \\
\hline 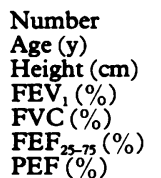 & $\begin{array}{r}54 \\
30.7(1.4) \\
159.9(0.7) \\
100.9(1.9) \\
101.2(1.7) \\
99.8(5.0) \\
99.4(2.5)\end{array}$ & $\begin{array}{r}54 \\
32.2(1.9) \\
159.3(0.7) \\
99.3(1.5) \\
98.9(1.7) \\
98.4(3.6) \\
100.6(2.2)\end{array}$ & $\begin{array}{r}22 \\
26.7(1.8) \\
160.4(1.0) \\
99.1(3.1) \\
97.9(2.9) \\
103.8(4.9) \\
95.9(3.4)\end{array}$ & $\begin{array}{r}22 \\
26.7(1.8) \\
158.8(1.2) \\
97.9(2.0) \\
97.8(2.4) \\
95.3(5.0) \\
100.9(4 \cdot 3)\end{array}$ \\
\hline
\end{tabular}

There are no significant differences between passive and non-exposed subjects (one tailed $t$ test).

Abbreviations as in table 1 .

as a whole or between the age matched subjects. No significant differences emerged from further analysis of subgroups of passive smokers by comparison with control subjects.

\section{Discussion}

There is no doubt about the adverse health consequences of cigarette smoking among smokers. Several reports have shown the deleterious effect of cigarette smoking on pulmonary function in individuals who smoke. ${ }^{18-20}$ Dockery et $a l^{11}$ found a larger reduction in FEV than FVC among smoking adults and a greater reduction in men than in women. Our study documents an adverse effect on pulmonary function in men exposed to environmental tobacco smoke.

Exposure to cigarette smoke or passive smoking is gaining more attention because of its appreciable public health effects. Environmental tobacco smoke is a combination of sidestream smoke and exhaled mainstream smoke. Owing to a lower temperature of combustion, side stream smoke contains larger concentrations of ammonia, benzene, carbon monoxide, nicotine, and various carcinogens (2-naphthylamine, 4-aminobiphenyl, $n$ nitrosamine, benz(a)-anthracene, and benzopyrene) than does mainstream smoke. ${ }^{1}$ Many studies have shown a reduction in pulmonary function values among children of smoking parents. These include reductions in $\mathrm{FEV}^{6711}$ and $\mathrm{FVC}^{6}$ in boys and in $\mathrm{FEF}_{25-75}$ in girls ${ }^{689}$ or both sexes. ${ }^{10}$ Some studies have not found a significant effect of parental smoking on children's pulmonary function. ${ }^{922}$ The Surgeon General has concluded that the children of parents who smoke have smaller

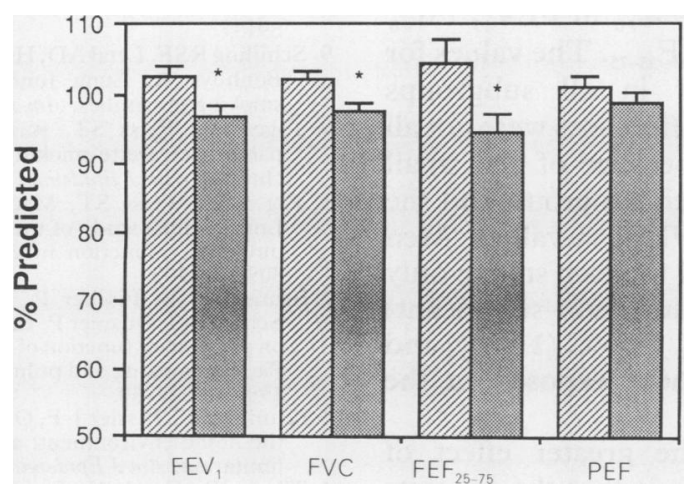

Figure 1 Pulmonary function values in non-exposed subjects (四) and passive smokers (). rates of increase in lung function as the lung matures. ${ }^{1}$

Several studies have evaluated the effects of passive smoking on pulmonary function in adults. White et $a^{14}$ reported small airways dysfunction with a $14 \%$ reduction in $\mathrm{FEF}_{25-75}$ in non-smokers exposed to environmental tobacco smoke; a fall of $5 \%$ in $\mathrm{FEV}_{1}$ and of $3 \%$ in FVC was not significant. Kauffman et $a^{13}$ studied the effect of exposure to cigarette smoke at home on pulmonary function in French men and women but they did not control for exposure in the workplace. There was a reduction of $3 \%$ in FVC, $4 \%$ in $\mathrm{FEV}$, and $6 \%$ in $\mathrm{FEF}_{25-75}$ among women; men exposed to passive smoke at home showed a $6 \%$ fall in $\mathrm{FEF}_{25-75}$ and a non-significant $4 \%$ fall in $\mathrm{FEV}_{1}$. Masi et $a^{16}$ found adverse effects of passive smoking on $\mathrm{FEF}_{25-75}$ in young men (aged 1535) and on carbon monoxide transfer factor in young women. Other studies have not found significant effects on pulmonary function of exposure to tobacco smoke in adults. ${ }^{912} 15$

Our study shows a significant reduction in \% predicted $\mathrm{FEV}_{1}(5 \cdot 7 \%)$, FVC $(4.6 \%)$, and FEF $_{25-75}(9.9 \%)$ in male passive smokers by comparison with non-exposed men, but no

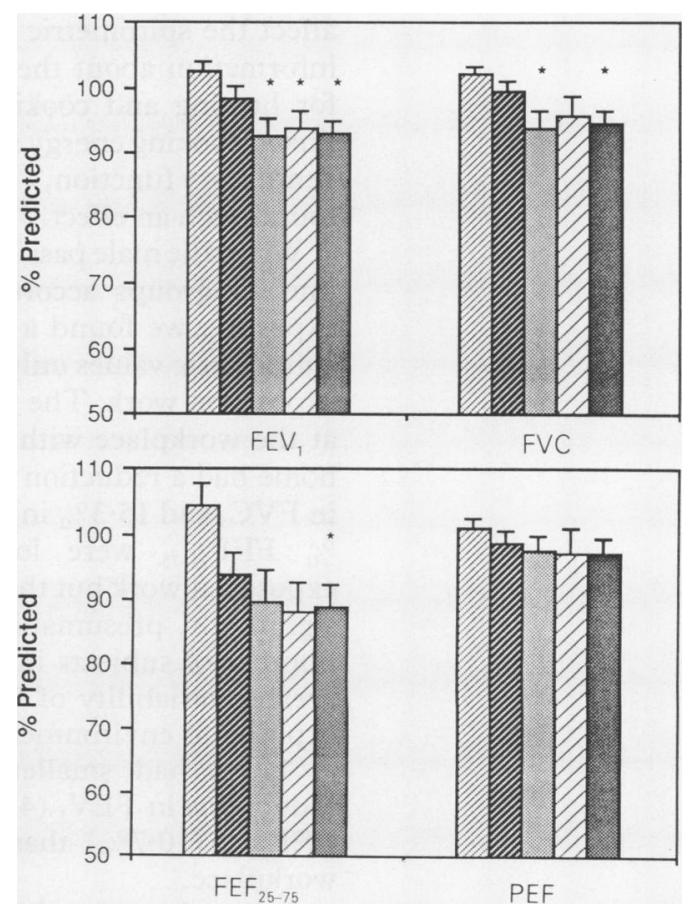

Figure 2 Pulmonary function values in non-exposed subjects (U/A) and in passive smokers exposed at home only $($ Ua), at work only (1) , at home and at work $(1 /$,$) , and$ at work whether or not at home (u). ${ }^{\star} p<0.05$. 
differences were found in the women. The reductions were even greater among age matched male passive smokers $\left(7.3 \%\right.$ in $\mathrm{FEV}_{1}$, $5.1 \%$ in FVC, and $15.4 \%$ in $\left.\mathrm{FEF}_{25-75}\right)$. The PEF was significantly reduced $(6.4 \%)$ only in the age matched group. Thus we found somewhat larger increments in $\mathrm{FEV}_{1}$ and FVC than did Kauffmann et $a l^{13}$ and White et $a l,{ }^{14}$ but smaller decrements in $\mathrm{FEF}_{25-75}$ than White et al.

One explanation for the larger decrements observed in our study could be that there was a greater exposure to environmental tobacco smoke among our subjects. The strict selection criteria we used should reduce the variation due to other factors, making detection of significant effects due to passive smoking more likely. For example, the standard deviations of $\%$ predicted $\mathrm{FEV}_{1}$ values among non-exposed and passive smoking men were $17.5 \%$ and $17.2 \%$ in the study of White et al,,$^{14}$ but only $12.6 \%$ and $11.4 \%$ in our study. The standard deviations of the observed-predicted values were similar to those in other studies of normal subjects, ${ }^{2324}$ indicating that the variability in our study is what would be expected for normal individuals. Although other studies excluded individuals with current respiratory signs and symptoms, most did not exclude those with hay fever, allergic symptoms, or a past history of asthma. We included only normal subjects without a history of smoking and excluded all of those who had signs and symptoms of conditions that could affect the spirometric values.

As most subjects were unable to quantify the amount of exposure to passive smoke, we could not relate pulmonary function to the number of years or hours per day of exposure to cigarette smoke. All the subjects were living in Tehran, an area high in air pollution, but none gave a history of occupational exposure that would affect the spirometric values. We do not have information about the sources of energy used for heating and cooking. Some reports have linked cooking energy sources to impairment of ventilatory function, ${ }^{46}$ whereas others have not found such an effect. ${ }^{15}$

When the male passive smokers were divided into subgroups according to their source of exposure, we found a significant reduction in spirometric values only among those who were exposed at work. The group exposed to smoke at the workplace with or without exposure at home had a reduction of $9.4 \%$ in $\mathrm{FEV}_{1}, 7.6 \%$ in FVC, and $15 \cdot 3 \%$ in $\mathrm{FEF}_{25-75}$. The values for $\%$ FEF $_{25-75}$ were lower in all subgroups exposed at work but the differences were not all significant, presumably because of the small number of subjects in each subgroup and the greater variability of $\% \mathbf{F E F}_{25-75}$ values. Men exposed to environmental tobacco smoke only at home had smaller (and non-significant) reductions in $\mathrm{FEV}_{1}(4.2 \%)$, FVC $(1.8 \%)$, and FEF $_{25-75}(10.7 \%)$ than those exposed in the workplace.

An explanation for the greater effect of exposure at the workplace is that the subjects would be exposed for about eight hours, whereas at home the actual contact and exposure to cigarette smoke is shorter. None of the study subjects reported occupational exposures to hazardous substances. An argument could be made that labourers are more likely to be exposed to unknown agents that would adversely affect pulmonary function. Although the distribution of occupations between the passive smoking and the nonexposed males was similar, 18 non-exposed males were labourers compared with nine passive smokers. If labourers had unknown exposures leading to worse pulmonary function the effects of passive smoking would be greater than we found. We suggest that the reason no differences were found among women was that only eight were exposed to passive smoke at work, compared with 31 men.

In conclusion, our study has shown a significant reduction in spirometric values among men exposed to environmental tobacco smoke. Men exposed at work with or without exposure at home showed the greatest reduction. The adverse effects of passive smoking on pulmonary function in adults emphasises the importance of preventing exposure of nonsmokers to cigarette smoke.

M-R $M$ was on sabbatical leave from the Iran University of Medical Sciences, Tehran. D C J was supported by National Institute of Health clinical investigator award HL01166.

1 US Department of Health and Human Services. The health consequences of involuntary smoking. A report of the Surgeon General. Washington, DC: US Department of Health and Human Services, Center for Health Promotion and Education, Office on Smoking and Health, 1986.

2 Fielding JE, Phenow KJ. Health effects of involuntary smoking. N Engl J Med 1988;319:1452-60.

3 Weiss ST, Tager IB, Schenker M, Speizer FE. The health effects of involuntary smoking (state of the art). Am Rev Respir Dis 1983;128:933-42.

4 Samet JM, Marbury MC, Spengler JD. Health effects and sources of indoor air pollution, part I (state of the art). $\mathrm{Am}$ Rev Respir Dis 1987;136:1486-508.

5 Tager IB. Passive smoking and respiratory health in children. Sophistry or cause for concern? [Editorial]. $\mathrm{Am}$ Rev Respir Dis 1986;133:959-61.

6 Burchfiel CM, Higgins MN, Keller JB, Howatt WF, Butler WJ, Higgins ITT. Passive smoking in childhood. Respiratory conditions and pulmonary function in Tecumseh, Michigan. Am Rev Respir Dis 1986;133:966-73.

7 Ware JH, Dockery DW, Spiro III MA, Speizer FE, Ferris BG, Jr. Passive smoking, gas cooking, and respiratory health of children living in six cities. Am Rev Respir Di 984;129:366-74

8 Tashkin DP, Clark VA, Simmons M, et al. The UCLA population studies of chronic obstructive respiratory disease. VII. Relationship between parental smoking and children's lung function. Am Rev Respir Dis 1984;129. 891-7.

9 Schilling RSF, Letal AD, Hui SL, Beck GJ, Schoenberg JB, Bouhuys A. Lung function, respiratory disease and smoking in families. Am J Epidemiol 1977;106:274-83.

10 Tager IB, Weiss ST, Rosner B, Speizer FE. Effect of parental cigarette smoking on the pulmon

11 Tager IB, Weiss ST, Manoz A, Rosner B, Speizer FE Longitudinal study of the effects of maternal smoking on Longitudinal study of the effects of maternal smoking on
pulmonary function in children. $N$ Engl J Med 1983; pulmonary fu

12 Brunekreef B, Fischer P, Remijn B, Van der Lende R, Schouten J, Quanjer $P$. Indoor air pollution and its effects on pulmonary function of adult non-smoking women: III Passive smoking and pulmonary function. Int J Epidemiol 1985;14:225-30

13 Kauffman F, Tessier J-F, Oriol P. Adult passive smoking in the home environment: a risk factor for chronic airflow imitation. Am J Epidemiol 1983;117:269-80

14 White JR, Froeb $H$. Small airways dysfunction in nonsmokers chronically exposed to tobacco smoke. $N$ Engl Med 1980;302:720-3.

15 Comstock GW, Meyer MB, Helsing KJ, Tockman MS 
Respiratory effects of household exposures to tobacco smoke and gas cooking. Am Rev Respir Dis 1981;124: 143-8.

16 Masi JA, Hanley JA, Ernst P, Becklake MR. Environmental exposure to tobacco smoke and lung function in young adults. Am Rev Respir Dis 1988;138:296-9.

17 Gardner RM, Hankinson JL, West BJ. Evaluating commercially available spirometers. Am Rev Respir Dis 1980; 102:73-82.

18 US Department of Health and Human Services. The health consequences of smoking: chronic obstructive lung disease. Washington, DC: USGPO, 1984.

19 Anderson DO, Ferris BG Jr. Role of tobacco smoking in the causation of chronic respiratory disease. $N$ Engl J Med 1962;267:787-94.

20 Tager IB, Munoz A, Rosner B, Weiss ST, Carey V, Speizer
FE. Effect of cigarette smoking on the pulmonary function of children and adolescents. Am Rev Respir Dis 1985;131:752-9.

21 Dockery DW, Speizer FE, Ferris BG Jr, Ware JH, Louis TA, Spiro III A. Cumulative and reversible effects of lifetime smoking on simple tests of lung function in adults. Am Rev Respir Dis 1988;137:286-92.

22 Lebowitz MD, Knudson RJ, Burrows B. Family aggregation of pulmonary function measurements. Am Rev Respir Dis 1982;129:8-11.

23 Morris JF, Koski A, Johnson LC. Spirometric standards for healthy nonsmoking adults. Am Rev Respir Dis 1971 103:57-67.

24 Crapo RO, Morris AH, Gardner RM. Reference spirometric values using techniques and equipment that meet ATS recommendations. Am Rev Respir Dis 1981;123:659-64. 